\title{
Environmental Regulation and Trade Openness in the Presence of Private Mitigation ${ }^{1}$ \\ (Forthcoming in Journal of Development Economics)
}

\author{
Louis Hotte ${ }^{2} \quad$ Stanley L. Winer ${ }^{3}$
}

December 2010

\footnotetext{
${ }^{1}$ We thank Sophie Bernard, Cinzia Di Novi, Ruth Forsdyke, Michael Kevane, Bryan Paterson, Stéphane Straub, an anonymous referee and the editor for helpful comments. We also thank seminar participants at CERDI-Université d'Auvergne, Université Paris 1 Pantheon-Sorbonne, the University of Ottawa, Université de Rouen, the University of Western Ontario, the University of Eastern Piedmont, Georgia State University, Hohenheim University and participants in meetings of the CSAE, the CEA, CREE and the IIPF, as well as the Montréal Natural Resources and Environmental Economics Workshop. Winer's research was partly supported by the Canada Research Chair Program. This work was also supported by a research grant from the SSHRCC.

${ }^{2}$ Department of Economics, University of Ottawa (louis.hotte@uottawa.ca)

${ }^{3}$ School of Public Policy and Administration and Department of Economics, Carleton University, CESifo and ICER (stan_winer@carleton.ca)
} 


\section{Abstract \\ Environmental Regulation and Trade Openness in the Presence of Private Mitigation}

Acknowledging the differential ability of individuals to privately mitigate the consequences of domestic pollution for their health is essential for an understanding of their demands for regulation of the environment and of trade in dirty goods, and for analysis of the implications of these demands for equilibrium policy choices. In a small open economy with exogenous policy, we first explain how private mitigation at a cost results in an unequal distribution of the health consequences of pollution in a manner consistent with epidemiologic studies, and consequently how the benefits and costs of trade in dirty goods interact with choices concerning private mitigation to further polarize the interests of citizens concerning environmental stringency. The economy is then embedded in a broader political economy setting, and simulated to investigate the role of private mitigation in shaping political equilibria. We show that when citizens can choose between mitigating the health consequences of domestic pollution privately and reducing pollution through public policy, the same polarization of interests underlies equilibrium policy choices in both democratic and autocratic regimes.

Keywords: Environmental regulation; Pollution; Private mitigation, Defensive measures, Avoidance activities; Health; Trade; Dirty goods; Individual welfare; Democracy; Representation theorem; Autocracy.

JEL classification: D7, F18, Q56 


\section{Introduction}

In this paper we analyze the demands by individuals of varying incomes for regulation of the environment and of trade, and the implications of these demands for equilibrium public policy choices. The economic setting is that of a small open economy producing two tradable goods, one of which is polluting, where more stringent environmental control reduces income. The differential ability of individuals to privately mitigate the consequences of domestic pollution for their health at a cost is a key characteristic of the analysis throughout. ${ }^{1}$

News stories about how the poorest within developing countries are most affected by domestic pollution are legion. ${ }^{2}$ In fact, many epidemiologic studies confirm that those with lower socioeconomic status tend to suffer a heavier health burden from pollution. (See Jayachandran 2008, Pearce et al. 2006, Evans and Smith 2005, Brunekreef and Holgate 2002, Neidell 2004, and Brooks and Sethi 1997 among others). We might therefore expect that within a country, individual demands for environmental regulation will be more intense among lower income groups, as the evidence provided by Kahn and Matsusaka (1997) and Kristrom and Riera (1996) appears to confirm. Similarly, when a country's comparative advantage lies with the production of goods that are pollution intensive, we might expect opposition to trade openness among lower income citizens to be relatively stronger.

On the other hand, it is often argued that environmental quality is a normal good - that richer individuals are willing to pay more for a cleaner environment. If that is the case, then poorer people will demand laxer environmental regulation and more trade with specialization in dirty production than will the rich. Such is the basic reasoning behind Summers' provocative 1991 memo at the IMF, which put forward the idea that it may make sense for dirty industries to move South. ${ }^{3}$

\footnotetext{
${ }^{1}$ In accordance with the related literature, we define private mitigation as measures that attenuate the adverse consequences of given pollution levels for a person's health. The expressions avoidance, averting and defensive measures are similarly used. More recently and in the context of climate change, the term adaptation is being used, though with a more general application.

${ }^{2}$ See Bernard 2006, Bradsher and Barboza 2006, French 2005 or The Economist 2005.

${ }^{3}$ In the theoretical literature, Copeland and Taylor (1994) show that if the normal-good argument is accepted, then a representative individual in a poor country optimally chooses lower environmental standards and thus favors specialization in dirtier industries. The other key assumption here is that all externalities are somehow internalized. If that is not the case, and at the other end of this normative literature, are the analyses of Pethig (1976) and Chichilnisky (1994) who take as given that environment standards are lower in developing countries, and argue that although these countries attract dirtier industries, one cannot be sure that trade does not lower welfare; it depends on what drives the choice of standards. On trade and endogenous internalization, see Hotte, Long and Tian (2000) and Copeland (2005). Finally, we note that while this normative literature informs our work, our concern is with positive aspects of how individual interests are shaped and the role such demands play in shaping equilibrium policy outcomes.
} 
There are good reasons to believe that environmental quality is a normal good in many contexts. But in the light of the epidemiologic studies, that this means that poorer individuals always demand less stringent environmental regulation and more open trade in domestically produced dirty goods does not seem sensible. Indeed, another straightforward application of the normal good argument also leads one to infer that wealthier individuals in developed countries always demand more restricted trade in polluting goods than do the poor.

In this paper we regard these contrasting views as special cases that may arise within a more general framework of analysis. We begin with the idea that it is not environmental quality per se which is a normal good, but rather it is the health condition associated with it. And once this consideration is combined with the fact that the impact of pollution on health can be privately mitigated at a cost, ${ }^{4}$ there are far-reaching implications for our understanding of the relationships between environmental regulation, trade openness and individual interests, including reconciliation of the views above.

To expose and explore these implications, we consider a small open economy with Ricardian production technology in which individuals differ by income levels, along with its autarkic counterpart. The model is simplified so that closed-form derivation and comparison of economic equilibria are possible. Here the choice between trade with specialization in the polluting good versus autarky serves as a simplified policy option regarding the regulation of trade openness. This economic model (where policies are exogenously determined) allows for closed form inter-personal comparisons of the impact of environmental regulation even when pollution control interacts with the benefits of trade openness. ${ }^{5}$ The economy is then embedded in a broader political economy setting, and simulated to further investigate the role of private mitigation in the determination of public policy choices.

We show at the outset that the availability of private mitigation results in an unequal distribution of the health consequences of pollution across income groups in a manner consistent with epidemiologic studies. This stands in contrast to the related literature, where the effects of pollution are uniformly born across the population. (See Fredriksson 1997, Aidt 1998, Schleich 1999, McAusland 2003 and Copeland and Taylor 2003.) Exceptions to the equal burden assumption include Copeland and Taylor $(2003 ; \S 7.3)$, where it is assumed that people's tastes about the environment differ exogenously and without relation to income. To the best of our knowledge, Eriksson and Persson (2003) provide the only study in which the negative effects

\footnotetext{
${ }^{4}$ For analysis of consumer behavior in the presence of private mitigation, see Courant and Porter (1981), Shibata and Winrich (1983), Bartik (1988) and McKitrick and Collinge (2002).

${ }^{5}$ The same qualitative effects would be present with the more general Heckscher-Ohlin framework, but this would come at a cost in terms of insight and clarity. One should also note that, as Feenstra (2004) points out, " ... the Ricardian model is as relevant today as it has always been." (p. 1)
} 
of pollution decline with income. However, while the extent to which the adverse consequences of pollution are privately attenuated is explicitly modeled in our paper, these authors assume that the distribution of the burden of pollution is exogenously determined, and they do not consider trade.

Costly private mitigation leads to the polarization of the interests of rich and poor with respect to the stringency of regulation, in a manner that we investigate in detail. The interaction of individual decisions about private mitigation with the consequences of trade openness exacerbates this divergence. We also show that when trade leads to a more polluted environment compared to autarky, the demands for public action to control pollution by high-income individuals may decrease. This is because the additional income that trade generates allows the rich to better insulate themselves from the heath consequences of pollution. Moreover, since the gains from trade may be weaker for lower income individuals, trade in dirty goods may lead to a strengthening of the poor's demand for environmental regulation. In such situations, a simple normal-good-based prediction about pollution will not always serve as an accurate guide to the nature of individual interests in the open economy.

It is reasonable to expect that this polarization of interests will carry with it implications for the outcome of political competition. The reason is that introducing private mitigation possibilities alters individual incentives to seek costly collective as opposed to costly private actions as a way of dealing with environmental degradation. To study the role of private mitigation in a political context, we simulate the equilibrium relationship between environmental regulation, trade and welfare for two income groups in fully democratic and in autocratic regimes differentiated by the presence or absence of political voice for poorer citizens. The economic structure analyzed in the first parts of the paper is embedded in the model used, and the role of private mitigation is studied by varying its effective cost.

We show that the costliness of private mitigation or, equivalently, the nature of the pollutant, is a key factor underlying the equilibrium choice of policy towards the environment and towards trade. When private mitigation is infeasible, fully democratic and autocratic regimes in which the poor have no voice tend to adopt the same levels of regulation and of trade openness. But with costly private mitigation, the interests of the mass of poorer voters in dealing publicly with environmental degradation diverge from the those of the rich, and the outcome in the fully democratic setting involves more regulation than in an autocracy. In this way we see that the importance of the interaction of individual choices about private mitigation and trade openness uncovered in the economic model with exogenous policy carries over to the equilibrium policy context.

Other authors - for example, Congleton (1992) and Winslow (2005) - argue that democracy is good for the environment because elites have a greater share of any income generated by the production of dirty goods, as they do in the model developed 
here. Here we show why not just inequality, but also the presence of costly private mitigation must be acknowledged in the political economy of environmental policy.

In the broader political economy context, we also suggest how cases may even arise where the poor may oppose trade openness in a democracy even though it has the potential to benefit everyone, because of a concern that laxer environmental regulation with trade will then be imposed in the interests of richer citizens. Such an argument is consistent with the shift of emphasis from anti- to alter-mondialisation among some (French and other) globalization protest movements. They do not oppose trade per se, but rather the type of trade that they observe.

The paper is organized as follows. In section 2, we introduce the fundamental functions representing individual welfare as well as the production, regulation and private pollution-mitigating technologies. We solve for decentralized consumption and production decisions in section 3. Those decisions are combined with the market-clearing conditions in section 4, for both autarky and for trade, and the resulting effects on pollution are derived. In section 5 we compare the marginal welfare consequences of environmental regulation for different income groups in the economic equilibrium. Here we also describe how trade openness may create conflicting demands for environmental regulation. In section 6 , we introduce the political economy setting for the determination of policy choices and we then analyze political equilibria in several scenarios differentiated by the costliness of private mitigation. Section 7 concludes our analysis of the role of private mitigation of the consequences of pollution in the relationship between environmental policy, trade openness and economic well-being.

\section{The economic model}

\subsection{Individual income and welfare}

The economy is composed of a continuum of individuals indexed by $i \in[0,1]$ and distributed according to density function $f(i)$. The total population size is normalized to one. A priori, individuals differ solely by their claim on the national income $Y$, which is expressed as the exogenous share $\alpha(i)>0$. Individual income is thus

$$
y(i)=\alpha(i) Y \text {. }
$$

Individuals are ranked so that $\alpha(i)$ is non-decreasing in $i$.

Note that since relative factor endowments play no role, we depart from the manner in which the political economy of trade is often studied. The reason is that in

our framework, individual interests depend importantly on the ability to privately attenuate the effects of pollution on health, and this ability is a function of income, whatever its source. 
An individual $i$ 's welfare level $U(i)$ depends positively on his or her health condition, $H(i)$, and the quantity of goods and services consumed, $x(i)$. We assume that the two are separable and exhibit decreasing marginal utility of consumption. Thus (where subscripts denote partial derivatives): $U(i)=u(x(i))+H(i), u_{x}>0, u_{x x}<0$.

In turn, the health condition depends negatively on the economy-wide pollution level $Q \geq 0$, the effect of which can be privately mitigated or reduced with effort level $d(i)$. Hence, $H(i)=H(d(i), Q), H_{Q} \leq 0$ and $H_{d} \geq 0$. Note that $Q$ is the economy wide level of domestic pollution, and so does not include transboundary pollution such as greenhouse gases.

A crucial feature of the model is that there are two channels through which an individual's health can be improved: privately with higher $d(i)$, or collectively with a lowering of $Q$. Examples of private actions to mitigate the consequences of pollution include choice of house location, installation of a household water filtration system, drinking bottled water, fetching water at a distance, chlorine pills, using air cleaning systems, taking weekends at the mountain, using asthma medicines, and so on. (See Neidell 2004, Hanna 2007 and Rosado 2006).

For tractability, we use the following functional forms in the ensuing analysis: $u(x(i))=\ln (x(i))$ and $H(i)=-\left[\delta_{0}-\delta_{1} d(i)\right] Q$, where parameter $\delta_{0}$ denotes the marginal effect of pollution on health in the absence of resources spent on private mitigation, and parameter $\delta_{1}$ summarizes the available private mitigation technology. We thus have

$$
U(i)=\ln (x(i))-\left[\delta_{0}-\delta_{1} d(i)\right] Q, \quad d(i) \in\left(0, \delta_{0} / \delta_{1}\right) .
$$

In the absence of pollution $(Q=0)$, or with maximum private mitigation $(d(i)=$ $\left.\delta_{0} / \delta_{1}\right), i$ 's health condition attains its best state $(H(i)=0)$. Otherwise, if $Q$ increases while $d(i)$ is fixed, the health condition worsens and the same holds if $d(i)$ decreases while $Q$ is fixed. Because consumption exhibits decreasing marginal utility, the health condition is a normal good. A rise in income induces one to spend more on improving his health condition.

Note finally that as $\delta_{1} \rightarrow 0$, private mitigation becomes technologically impossible (or, equivalently, infinitely costly). In that case, with $H(i)=\delta_{0} Q$, the fact that health is a normal good is sufficient to make environmental quality a normal good.

\subsection{Production, and private expenditure}

We assume an economy with two types of goods, denoted 1 and 2. Good 2 is a dirty good in the sense that its production creates pollution while good 1 is clean and does not pollute at all. Production uses a Ricardian technology embodied in the following national production possibility frontier or PPF:

$$
Z_{2}=\hat{Z}_{2}-b Z_{1}
$$


where $Z_{2}$ and $Z_{1}$ respectively denote the aggregate outputs of goods 2 and 1 , parameter $b$ is the constant opportunity cost of producing an extra unit of good 1 in terms of good 2, and $\hat{Z}_{2}$ measures the height of the PPF (an index of the country's total production capacity or wealth). With good 2 as the numéraire good and good 1 selling at price $p$, the national income is

$$
Y=p Z_{1}+Z_{2} \text {. }
$$

Goods 1 and 2 are combined as imperfect substitutes for the creation of a final good $C(i)$ using the Cobb-Douglas form: $C(i)=C_{1}(i)^{a} C_{2}(i)^{1-a}$, where $C_{1}(i)$ and $C_{2}(i)$ respectively denote the quantities of goods being combined. The unit cost of a final good is thus $c(p)=a^{-a}(1-a)^{a-1} p^{a}$, and we can then write the individual budget constraint as $y(i)=c(p) C(i)$.

Final goods are used either for consumption level $x(i)$ or private pollution mitigation effort $d(i)$ so that $x(i)+d(i)=C(i)$. Here we are implicitly assuming that the consumption bundle and the pollution mitigation effort bundle are equally pollution intensive, as there is no a priori reason to believe that defensive pollution measures are more or any less pollution intensive than the mix of consumption goods on average.

Now let consumption expenditures be expressed as $e(i)=c(p) x(i)$. The individual budget constraint can then be rewritten as

$$
e(i)=\alpha(i) Y-c(p) d(i) .
$$

\subsection{Pollution and its regulation}

In the absence of environmental regulation, the economy-wide pollution level $Q$ is simply given by $Q=Z_{2}$; that is, each unit of good 2 produces one unit of pollution. Environmental regulation requires the suppliers of good 2 to produce in a cleaner way. Some productive resources must be devoted to either cleaning up along the production process or using cleaner production techniques. Either way, in comparison to the nointervention case, environmental regulation has two direct effects: (1) A benefit in the form of less pollution for any production level $Z_{2}$; and (2) A cost in the form of more inputs necessary to achieve any production level $Z_{2}$.

Let us define the stringency of environmental regulation as a continuous variable $\theta \in[0,1] . \theta=0$ imposes no restriction on emissions, while $\theta=1$ is an obligation to abate all emissions. Here there is no uncertainty surrounding the effectiveness of environmental policy, and pollution affects only the domestic environment. The benefits and costs of regulation are represented as follows:

Benefit: $Q=h(\theta) Z_{2}$, with $h^{\prime}(\theta)<0, h(0)=1$ and $h(1)=0$;

Cost: $Z_{2}=(1-\theta)\left(\hat{Z}_{2}-b Z_{1}\right)$. 
Equation (7) implies that regulation results in a downward shift of the PPF: for any given amount of $Z_{i}$, less of $Z_{j}$ is produced. Moreover, a pollution-free output of good 2 is prohibitively costly. From a producer's point of view, environmental regulation simply increases the opportunity cost of producing the dirty good from $1 / b$ to $1 /(1-\theta) b$ in terms of the clean goods. The maximum amount of the clean good that can be produced is not affected by environmental regulation. We shall refer to equation (7) as the regulated production possibility frontier $R P P F$. It is illustrated in figure 1.

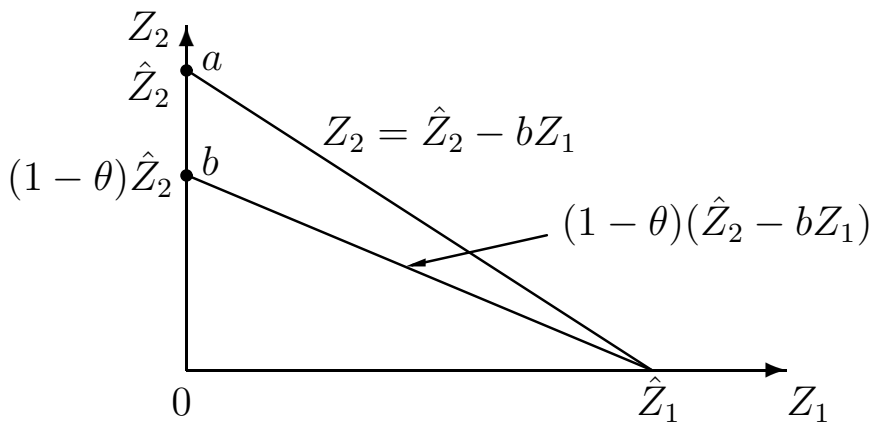

Figure 1: The regulated production possibility frontier (RPPF)

\section{Output and consumption decisions in autarky and with trade}

We assume price-taking behavior throughout. In autarky, under the assumption of Ricardian technology, the opportunity cost of good 1 is constant in terms of good 2 and equal to $(1-\theta) b$. Therefore, if both goods are produced, we have $p_{A}=(1-\theta) b$, where subscripts $A$ denotes autarky. The autarky national income is $Y_{A}=(1-\theta) b Z_{1}+Z_{2}$. Substituting the RPPF in (7), we obtain

$$
Y_{A}=(1-\theta) \hat{Z}_{2} \text {. }
$$

With trade, and in the small open economy that we explore, the price of good 1 is fixed at the world price $p_{T}$, where subscript $T$ denotes trade. There are two polar cases to consider: (i) specialization in the clean good, and (ii) specialization in the dirty good. Since specialization in the clean good removes pollution from our framework, it is not interesting in the present context and we shall not discuss this case further. When $p_{T}<(1-\theta) b$, there is full specialization in the dirty good. National income in this case is

$$
Y_{T}=(1-\theta) \hat{Z}_{2} \text {. }
$$


Note that whether $p_{T}$ is larger or smaller than $(1-\theta) b$ depends on the stringency of environmental regulation. The choice of $\theta$ ultimately depends on a political process which will be introduced later.

\subsection{Consumption and private mitigation decisions}

With the assumed Cobb-Douglas form for $C(i)$, the quantities demanded for goods 1 and 2 are, respectively, $a \alpha(i) Y / p$ and $(1-a) \alpha(i) Y$. We now have to solve for the allocation of expenditures between consumption goods $(e(i))$ and pollution mitigation $(c(p) d(i))$. To simplify, define $v(p) \equiv 1 / c(p)$ and substitute $x(i)=v(p) e(i)$ into the utility function so that the individual problem can be expressed as follows:

$$
\begin{aligned}
& \max _{\{e(i), d(i)\}} V(i)=\ln (v(p) e(i))-\left[\delta_{0}-\delta_{1} d(i)\right] Q \\
& \text { s.t. } e(i)=\alpha(i) Y-c(p) d(i) .
\end{aligned}
$$

The individual takes prices, pollution, environmental regulation and national income as given. Substituting $e(i)$ in (10) for the budget constraint, the problem of an individual reduces to choosing $d(i)$. The first-order condition for an interior solution is

$$
\frac{\partial V(i)}{\partial d(i)}=-\frac{c(p)}{e^{*}(i)}+\delta_{1} Q=0,
$$

where superscript ${ }^{*}$ denotes an individually optimal choice. (It is straightforward to verify that the second-order conditions for a maximum are satisfied.) This condition simply equates the marginal welfare loss from a lower consumption level to the health gain from an increase in the pollution mitigation effort. Given that $0 \leq d(i) \leq \delta_{0} / \delta_{1}$, the following interior and corner solutions apply to the choice of $d(i)$ :

$$
\begin{aligned}
& d^{*}(i)=0 ; \quad e^{*}(i)=\alpha(i) Y \quad \text { iff } \alpha(i) \leq \underline{\alpha}, \\
& d^{*}(i)=\frac{\delta_{0}}{\delta_{1}} ; \quad e^{*}(i)=\alpha(i) Y-c(p) \frac{\delta_{0}}{\delta_{1}} \quad \text { iff } \alpha(i) \geq \bar{\alpha}, \\
& d^{*}(i)=\frac{\alpha(i) Y}{c(p)}-\frac{1}{\delta_{1} Q} ; \quad e^{*}(i)=\frac{c(p)}{\delta_{1} Q} \quad \text { otherwise }
\end{aligned}
$$

where

$$
\begin{aligned}
\underline{\alpha} & =\frac{c(p)}{Y} \frac{1}{\delta_{1} Q} \\
\bar{\alpha} & =\frac{c(p)}{Y}\left[\frac{1}{\delta_{1} Q}+\frac{\delta_{0}}{\delta_{1}}\right] .
\end{aligned}
$$


According to corner solution (13), relatively poor individuals whose income share lies below $\underline{\alpha}$ choose not to spend anything on private mitigation because of their high marginal utility of consumption. Conversely, solution (14) denotes relatively wealthy individuals with income shares above $\bar{\alpha}$ who choose to be completely insulated from the effects of pollution. Interior solution (15) represents intermediate-income individuals who opt for a partial protection. From this solution, we see that optimal pollution mitigation efforts tend to increase with income and with the pollution level. We summarize this important fact with the following proposition:

Proposition 1 The individual pollution-mitigation effort (weakly) increases with pollution and with individual income.

\section{The general economic equilibrium in autarky, and with trade in dirty goods}

In autarky, the supply of each good must be equal to its aggregate demand. We thus have

$$
Z_{2 A}=\int_{0}^{1}(1-a) Y_{A} \alpha(i) f(i) d i=(1-a)(1-\theta) \hat{Z}_{2},
$$

where the right-hand term is obtained using expression (8) for the national income. In autarky, given $\theta$, the economic general equilibrium is fully described by the following set of equations:

$$
p_{A}=(1-\theta) b ; Z_{2 A}=(1-a) Y_{A} ; Z_{1 A}=\frac{a Y_{A}}{p} ; Q_{A}=h(\theta) Z_{2 A} ; Y_{A}=(1-\theta) \hat{Z}_{2}
$$

and $e^{*}(i)$ and $d^{*}(i)$ are defined according to either of conditions (13), (14) or (15). The system has 7 endogenous variables $\left\{p_{A}, Y_{A}, Z_{1 A}, Z_{2 A}, Q_{A}, e^{*}(i), d^{*}(i)\right\}$ and contains 7 equations.

With trade, when $p_{T}<(1-\theta) b$, the country produces only polluting good 2 . This trade equilibrium is summarized by the following system:

$$
Z_{1 T}=0 ; Z_{2 T}=(1-\theta) \hat{Z}_{2} ; Q_{T}=h(\theta) Z_{2 T} ; Y_{T}=(1-\theta) \hat{Z}_{2}
$$

with $e^{*}(i)$ and $d^{*}(i)$ being determined according to either of conditions (13), (14) or (15). Since the price is now exogenous, the economic system now has 6 endogenous variables $\left\{Y_{T}, Z_{1 T}, Z_{2 T}, Q_{T}, e^{*}(i), d^{*}(i)\right\}$ and 6 equations as well. For a given regulation level $\theta$, defining $\Gamma(\theta) \equiv h(\theta)(1-\theta)$, together with (19) and (20) then imply that

$$
\begin{aligned}
& Q_{A}(\theta)=(1-a) \Gamma(\theta) \hat{Z}_{2} \text { and } Q_{A}^{\prime}(\theta)=(1-a) \Gamma^{\prime}(\theta) \hat{Z}_{2}, \\
& Q_{T}(\theta)=\Gamma(\theta) \hat{Z}_{2} \text { and } Q_{T}^{\prime}(\theta)=\Gamma^{\prime}(\theta) \hat{Z}_{2} .
\end{aligned}
$$


We see that regulation affects pollution through two channels: the cleaner technology effect $h(\theta)$ and the higher production cost effect $(1-\theta)$. Since both tend to reduce pollution in equilibrium, we have $\Gamma^{\prime}(\theta)<0$. Pollution in autarky is a fraction $1-a$ of the trade level and so is the marginal effect of regulation. This difference is due to the fact that in autarky, the supply for each good must match its demand, thus determining the relative output proportions between the clean and dirty goods. With trade, however, demand and supply are disjoint, and in the case of a Ricardian production technology, full specialization in the production of the dirty good 2 results in a jump in pollution. Summarizing, we have that:

Proposition 2 Compared to autarky, an increase in pollution regulation stringency has a larger pollution-reducing impact when the country is open to trade and specialized in the dirty good.

Proposition 3 Compared to autarky and for a fixed regulation level, trade with specialization in the dirty good induces individuals to (weakly) increase their pollutionmitigation effort.

Proposition 3 follows directly from proposition 1 and the fact that trade leads to both more pollution and higher incomes.

\section{The individual welfare effects of environmental regulation in the eco- nomic equilibrium}

We now wish to analyze how an exogenous increase in the stringency of environmental regulation affects individual welfare in the general-equilibrium setting. (In the case of trade, we do so while assuming specialization in the dirty good only.) To this end, we make use of the following indirect utility function which can be obtained by direct substitution of the results in (13), (14) and (15):

$$
\begin{aligned}
& =\ln (v(p) \alpha(i) Y)-\delta_{0} Q \text { iff } \alpha(i) \leq \underline{\alpha} \\
V^{*}(p, y(i), Q) & =\ln \left(v(p) \alpha(i) Y-\frac{\delta_{0}}{\delta_{1}}\right) \text { iff } \alpha(i) \geq \bar{\alpha} \\
& =\ln \left(\frac{1}{\delta_{1} Q}\right)-\left[\delta_{0}-\delta_{1}\left(\frac{\alpha(i) Y}{c(p)}-\frac{1}{\delta_{1} Q}\right)\right] Q \text { otherwise. }
\end{aligned}
$$

In general, we have that:

$$
\frac{d}{d \theta} V^{*}(p, y(i), Q)=\underbrace{\left[\frac{\partial V^{*}(i)}{\partial p} p^{\prime}(\theta)+\frac{\partial V^{*}(i)}{\partial y} \alpha(i) Y^{\prime}(\theta)\right]}_{\text {price-income effect }}+\underbrace{\left[\frac{\partial V^{*}(i)}{\partial Q} Q^{\prime}(\theta)\right]}_{\text {pollution effect }}
$$


The impact of of a marginal tightening of regulation on individual welfare reveals itself through prices, income and pollution. To gain insight, we analyze the priceincome effect, represented by the first term between square brackets, separately from the pollution effect, given by the second term between square brackets. We expect that this approach will also be useful for the conduct of empirical work.

In autarky and for trade with specialization in the dirty good, these conditions yield $^{6}$

$$
\begin{aligned}
& =-\nu_{k}\left\{\left[\frac{1}{1-\theta}\right]+\left[\delta_{0} \Gamma^{\prime}(\theta) \hat{Z}_{2}\right]\right\} \text { iff } \alpha(i) \leq \underline{\alpha}_{k}, \\
\frac{d}{d \theta} V_{k}^{*}(i) & =-\nu_{k}\left[\frac{\alpha(i) \hat{Z}_{2}}{e_{k}^{*}(i)}\right] \text { iff } \alpha(i) \geq \bar{\alpha}_{k}, \\
& =-\nu_{k}\left\{\left[\frac{\alpha(i) \hat{Z}_{2}}{e_{k}^{*}(i)}\right]+\left[\left(\delta_{0}-\delta_{1} d_{k}^{*}(i)\right) \Gamma^{\prime}(\theta) \hat{Z}_{2}\right]\right\} \text { otherwise }
\end{aligned}
$$

where $k \in\{A, T\}, \nu_{A}=1-a$ and $\nu_{T}=1$. In each case, the first term between square brackets denotes the price-income effect while the second one - when present - is the pollution effect. For $\alpha(i) \geq \bar{\alpha}_{k}$, the pollution effect is absent since those highest income individuals are completely insulated from pollution.

We begin by analyzing the individual pollution effects. We have the following:

Proposition 4 In both trade and autarky, the marginal pollution welfare gains from a more stringent pollution regulation (weakly) decrease with individual income share $\alpha(i)$.

In the case of corner solutions, the marginal pollution effect is independent of $\alpha(i)$, while in the interior solution, the marginal pollution effect is equal to $-\left(\delta_{0}-\right.$ $\left.\delta_{1} d_{k}^{*}(i)\right) Q_{k}^{\prime}(\theta)$. The proposition then follows from the fact that $d_{k}^{*}(i)$ is generally increasing in $\alpha(i)$. The intuition here is simply that richer individuals tend to be better insulated from the effects of pollution because of their mitigation efforts.

We now want to compare the importance of the pollution welfare effects of regulation when moving from autarky to trade. In this respect, two opposite effects arise. One the one hand, there is a higher pollution reduction effect with trade than autarky (proposition 2). On the other hand, individuals tend to (weakly) increase their private-mitigation effort with trade (proposition 3). We thus obtain the following result:

\footnotetext{
${ }^{6}$ In deriving the following equations, we make use of the fact that in the economic equilibrium, $p_{A}^{\prime}(\theta)=-b$ in autarky and $p_{T}^{\prime}(\theta)=0$ with trade, $Y_{A}^{\prime}(\theta)=Y_{T}^{\prime}(\theta)=-\hat{Z}_{2}$, as well as conditions $(21)$ and (22).
} 
Proposition 5 The pollution welfare effect of regulation is strictly of greater magnitude (in terms of utility in equilibrium) with trade than autarky for individuals whose income share is below some unique value $\dot{\alpha}$, while it is (weakly) less important for all the other, richer individuals.

Proof of this and following propositions is in the Appendix. Proposition 5 is a key result because it begins to inform us about how the economic equilibrium structures a divergence of interests among citizens. Whether the economy is opened to trade or not, the poorest segment of the population remains highly exposed to pollution. These people choose not to privately mitigate because of the high marginal utility of their consumption. Then given that trade causes more pollution, a marginal increase in the degree of regulation must have a larger beneficial effect on their health with trade than in autarky. For richer individuals, recall that by increasing real income and pollution, trade induces them to mitigate further. For those who receive a large enough share of aggregate income, the increased mitigation effort is so large that a marginal increase in the degree of regulation produces a smaller health gain with trade than in autarky. Figure 2 summarizes proposition 5.

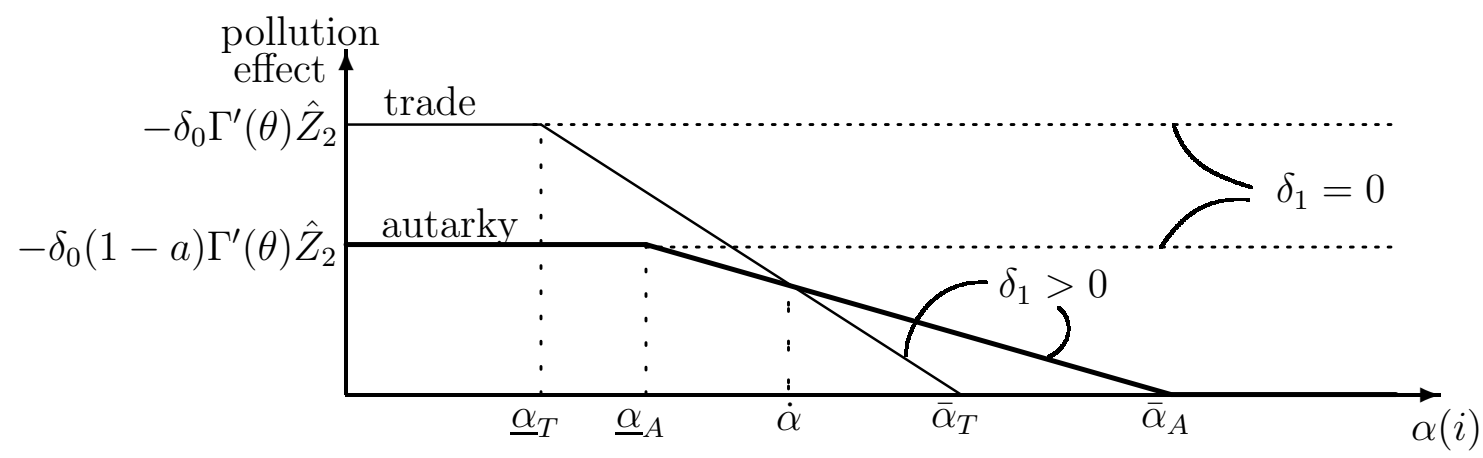

Figure 2: The marginal pollution welfare effect of regulation by income share for autarky and trade

\subsection{The price-income welfare effects of regulation}

In order to have a complete picture of the effects of regulation on individual welfare, we must also consider the price-income effect. To do so, we can begin with the following proposition: 
Proposition 6 The marginal price-income effect of regulation varies non-monotonically with income shares. In absolute terms, it is (weakly) increasing at low income shares (below $\bar{\alpha}$ ) and decreasing at high income shares (above $\bar{\alpha}$ ).

The best way to understand this result is by first observing that in the absence of private mitigation possibilities, the marginal price-income effect is the same regardless of income share. Indeed, even though those with higher income shares lose more from regulation in absolute terms, they also have a lower marginal utility of income, and the logarithmic form of utility that we use causes both effects to cancel out exactly. But once we introduce private mitigation possibilities, the diversion of expenditures away from consumption increases the marginal utility of income, so that there is now a net loss. The nonmonotonicity stems from the fact that the poorest segment of the population does not privately mitigate while for the very rich, private mitigation has little effect on their consumption. Hence, for these two extreme income share levels, the marginal price-income effect converges to the same value, as if private mitigation possibilities were absent. We also can assert the following:

Proposition 7 In absolute terms, the marginal price-income effect of regulation is greater in magnitude (in terms of utility in equilibrium) with trade than autarky for all income shares below or equal to $\bar{\alpha}_{T}$, as well as for arbitrarily large income shares.

The basic intuition here is that with specialisation in the production of the dirty good, regulating pollution is more costly with trade than autarky. There is one possible exception for the income shares around $\bar{\alpha}_{A}$. The ambiguity is caused by the fact that $\bar{\alpha}_{T}<\bar{\alpha}_{A}$ and that the marginal price-income effect is decreasing under trade for $\alpha(i)>\bar{\alpha}_{T}$ while in autarky, it increases up to $\bar{\alpha}_{A}$.

In figure 3, the curves labeled price-income loss illustrate propositions 6 and 7 for both trade and autarky. The pollution welfare effect anayzed previously also appears, where it is assumed that $1 /(1-\theta)<-\delta_{0} Q_{T}^{\prime}(\theta)$. (This inequality insures that in autarky, the lowest income individuals would prefer to have more stringent regulation.) We shall make use of this diagram further in what follows.

\subsection{Trade regimes and the demand for environmental regulation}

We now analyze how trade openness affects the aggregate demand for environmental regulation. In this section, we continue to take the regulation level as given and consider the marginal effect of regulation on welfare when moving from autarky to trade. In the following section, we shall compare welfare levels when the degree of regulation emerges from a political process. 


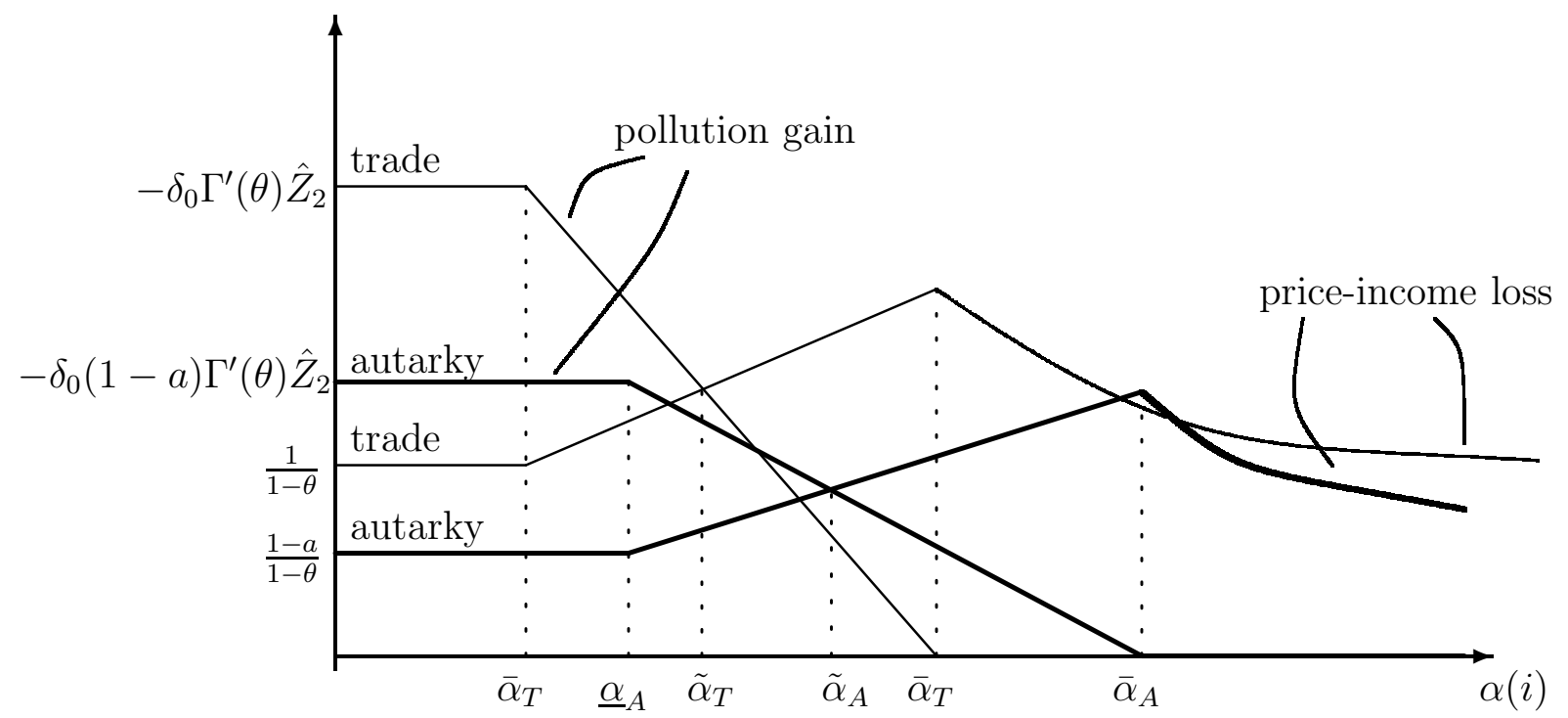

Figure 3: The marginal price-income welfare effect of regulation and the pollution welfare effect, by income share for autarky and trade

Note that in the analysis of individual demands for regulation, we shall consider both the number of individuals who demand stricter or laxer regulation and also variations in the intensity or depth of individual demands. Both numbers and intensity of demands play a role in the political process. We first have the following result:

Proposition 8 The proportion of individuals who demand more environmental regulation is lower with trade than autarky.

This proposition may appear counter-intuitive. Even though trade results in a more polluted environment, some individuals who in autarky preferred more stringent regulation now prefer less. But recall that the generation of more pollution constitutes only one channel through which trade affects the demand for regulation. One must also consider the price-income effect and the change in pollution-mitigation efforts that occur.

Under the assumptions of our model, the shift of expenditures from consumption to private mitigation induced by the higher pollution associated with open trade along with income gains makes individuals in the interior solution for $d_{A}^{*}(i)$ more sensitive to the price-income losses from regulation in comparison to the gains from lower pollution. This is illustrated in figure 3 above. In autarky, the indifferent 
individual who receives income share $\tilde{\alpha}_{A}$ of the national income is (locally) indifferent between more or less regulation as his price-income loss is exactly compensated by his pollution gain. Under trade, his pollution gain falls while the price-income loss increases, and he now prefers strictly lower regulation. Under trade, the indifferent individual is thus one who receives a strictly lower income share $\tilde{\alpha}_{T}$.

One may be tempted to infer from the above that open trade leads to less stringent regulation. But this assumes that government policy is driven by numbers of voters only. A more complete view will account for changes in the intensity of preferences. In this respect, we have the following proposition:

Proposition 9 For lower income individuals, the intensity of the demand for more stringent pollution regulation increases with trade. For high-income individuals and for a range of intermediate income levels, the intensity of the demand for less stringent pollution regulation increases with trade.

This is illustrated in figure 3 by the fact that the gap between the pollution gain from more regulation and the price-income loss grows larger the lower the income share of an individual, while those with high enough income lose more from additional regulation under trade than under autarky.

We therefore have that on the one hand, trade reduces the number of people demanding more regulation (proposition 8). On the other hand, trade increases the intensity of the demand for more stringent regulation by the poorest individuals, while simultaneously increasing the intensity of the demand for less stringent regulation by the richest individuals, as well as for some intermediate income levels (proposition 9). These effects are not revealed by a simple normal good argument about environmental quality. ${ }^{7}$ Moreover, if regulation is a result of a political process that responds to the demands of citizens, then merely looking at changes at the number of individuals who demand more regulation may not suffice. One must also account for the role of intensities of demand.

In this respect, we are left with an indeterminacy concerning the impact of trade on the stringency of environmental regulation that is adopted. The policy outcome will depend on how the political process effectively weighs the heterogeneous and conflicting demands of various voters. ${ }^{8}$ What we can say at this point, however, is still significant:

\footnotetext{
${ }^{7}$ It should also be noted that we do not deal here with how pollution control and pollution vary with mean income levels across countries, which is the subject of the Environmental Kuznets Curve (EKC), and our results are not inconsistent with it. Recent empirical results suggest that the EKC is driven mostly by how governance correlates with mean income (see, for example, Torras and Boyce (1998), Fredriksson et al. (2005), Farzin and Bond (2006) and Dasgupta et al. (2006)).

${ }^{8}$ This is consistent with the recent empirical evidence in Farzin and Bond (2006) and Dasgupta et al. (2006).
} 
Proposition 10 Trade exacerbates the divergence of interests over environmental regulation between low and high income individuals.

In this section, we analyzed the effects of marginal variations in environmental regulation on individual welfare. We decomposed the marginal welfare effects of regulation into its various sub-components. This procedure yields insight into how the possibility of private mitigation, interacting with trade openness, leads to divergence of interests in environmental regulation when policy choices are exogenous. In the next section we depart from the marginal analysis of the effects of given policy choices and broaden the framework of analysis to include the determination of policy and the level of welfare in a political equilibrium.

\section{The political-economy of environmental regulation in the presence of private mitigation}

We proceed by simulating equilibria in political settings in which the economic structure analyzed above is embedded. To bring out the role of private mitigation, we first consider situations in which the possibility of mitigation is prohibitively expensive for everyone, and then compare these outcomes to those that emerge when private mitigation is feasible at some cost.

Our principal interest is in the role of mitigation in a fully democratic process. As is well-known, the outcome of such a political process can be represented by maximization, over the set of available policy instruments, of a synthetic function $S$ that is a weighted sum of individual (indirect) utilities of the poor $V_{P}^{*}$ and of the rich $V_{R}^{*}$ (see for example, Coughlin and Nitzan 1981, Coughlin 1992, and Hettich and Winer 1999):

$$
S=s \eta_{P} V_{P}^{*}+(1-s) \eta_{R} V_{R}^{*}
$$

Here the economic structure outlined earlier has been substituted into the indirect utility functions. Maximization of (26) is carried out with respect to the degree of environmental regulation $\theta$ and trade openness (which in our framework is a discrete choice). To simplify, all individuals have been aggregated into two groups, poor $(P)$ and rich $(R)$, with population weights $s$ and $(1-s)$. The use of two income groups is sufficient to bring out the importance of the role of private mitigation. It is a simplification that has been used in other investigations, such as that by Acemoglu and Robinson (2006). The weights $\eta_{P}$ and $\eta_{R}$ reflect the effective political influence of the representative member of each group. These weights need not be identical, but we shall assume that they are in what follows, further strengthening our focus on the role of private mitigation. ${ }^{9}$

\footnotetext{
${ }^{9}$ On the difference between economic interests and political influence, see Hotte and Winer (2001).
} 
It is important to note that the form of the support function in (26) and the weights on utilities are the result of the political process, and that $S$ is not a social welfare function. Maximization of the support function (26) is just a convenient way of calculating an equilibrium. The intuition behind the representation theorem is this: if a political party or governing coalition in a fully competitive, democratic system does not propose or implement platforms that move society towards the Pareto frontier, it leaves open the possibility that the opposition can improve the welfare of voters and thereby increase its chances of electoral success. Competition insures that no such policy moves remain in equilibrium.

While policy choices are efficient in this formulation, the theorem can be generalized to allow for inefficient policy, for example by breaking the link between utility and voting behavior (see Hettich and Winer 1999, ch. 6). We are not concerned with these inefficiencies here.

To proceed further, we assume that the effect of environmental regulation on pollution is given by $h(\theta)=1-\theta$. We also need to choose parameters for the economic structure. The following values are ones that we have found to produce simulations that are illuminating: $b=1, \hat{Z}_{2}=3, a=0.5, \delta_{0}=2, p_{T}=0.1$. Finally, to set up the simulations, the poor and the rich respectively are assumed to make up $95 \%$ and $5 \%$ of the total population, the total size of which is normalized to one, with the income share of a rich individual set at eleven times that of a poor one, so that $\alpha_{R}=11 \alpha_{P}$.

\subsection{Equilibria without private mitigation}

We begin the simulations with the case in which $\delta_{1}=0$ so that private mitigation is impossible for anyone. The resulting zero mitigation equilibria are illustrated in figure 4. The first panel shows the welfare of the poor in autarky and in the open economy, the second panel shows the welfare of the rich, again in autarky and under trade. And panel three shows total political support $S$.

We see in the figure that in the absence of private mitigation, both groups prefer autarky over trade when the regulation level is low. This is because trade gains then cannot make up for the health losses that come with full specialization in the production of the dirty good. We note also that when $\theta \geq 0.9$, political support in a democracy, illustrated in the third panel, is constant under trade. Here there is a complete shift of specialization in the economy from the dirty good to the clean good, and so any further increase in regulation has no consequence for the welfare of voters.

The interests of the poor and the rich are aligned in the absence or infeasibility of private mitigation. Both groups globally prefer open trade with a pollution regulation level set at $\theta=0.7 .{ }^{10}$ Since both groups have the same interests with respect to public

\footnotetext{
${ }^{10}$ This welfare maximizing value for $\theta$ is approximate since we simulated the economy with discrete
} 

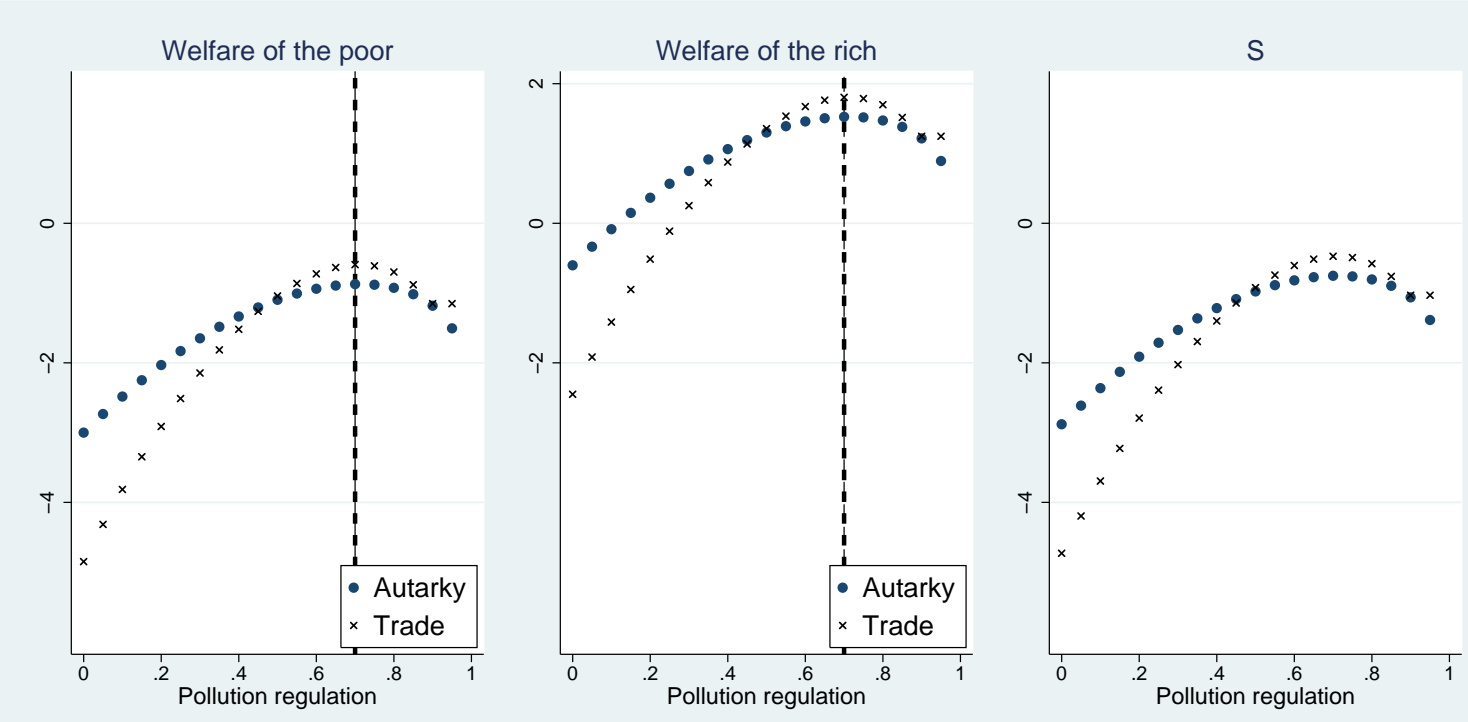

Figure 4: The welfare of the poor and the rich in autarky and trade, autocracy and democracy without private mitigation technology $\left(\delta_{1}=0\right)$

policy, autocracy and democracy lead to the same equilibrium policy choices. The simulation suggests the following proposition:

Proposition 11 In the absence of private mitigation, political equilibria tend to be the same under both democracy and autocracy, and both groups gain from trade openness.

\subsection{Equilibria when private mitigation is feasible}

Things are different when private mitigation is feasible at a cost, as illustrated by the simulations with $\delta_{1}=0.2$ shown in figure 5 . The interests of the rich and the poor are still aligned in autarky as in figure 4 (at point b in panel 1 and at $\mathrm{e}$ in panel 2). However, for the rich we see that the best option is to be opened to trade, and that trade openness be combined with the lowest regulation level (at point a in panel 2). The higher pollution from specialization that accompanies trade, combined with the higher income that results, induce the rich to spend so much on private mitigation that they are insulated fully from the effects of pollution, and they would then prefer to reduce regulation to its minimum in order to benefit fully from trade gains. Such an outcome turns out to be the worst for the poor who cannot afford to protect themselves (see point $d$ in panel 1). On the other hand, panel 2 indicates that

increments of $\theta$ of 0.05 . 

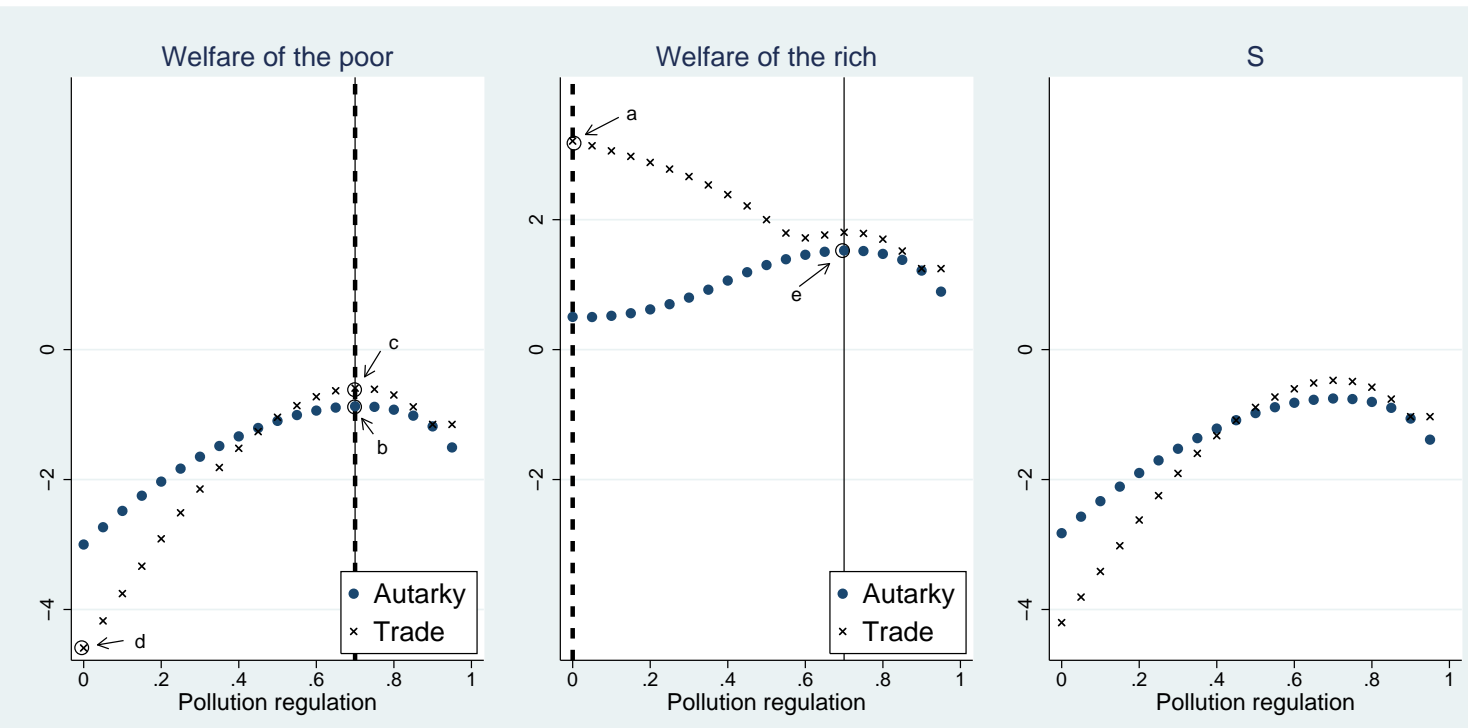

Figure 5: The welfare of the poor and the rich in autarky and trade, autocracy and democracy with private mitigation $\left(\delta_{1}=0.2\right)$

with trade openness and increasingly strict regulation, the rich eventually will choose not to privately mitigate anymore, if given the choice, because of the consequent fall in their income and in the level of pollution, and they thus would return to public regulation as a preferred choice for dealing with pollution. This explains the presence of two local welfare maxima for the rich illustrated in the second panel of figure 5 .

All of these outcomes are special cases of course. More generally, we can see from the simulations that when private mitigation is feasible, trade openness interacts with choices about private mitigation to polarize the interests of citizens.

How are these interests represented in the political equilibrium of autocracy and of the democratic state? We see from figure 5 that trade openness is chosen under both political regimes, because both the welfare of the rich (in the case of autocracy) and political support (in the democratic case) are highest then. But environmental regulation levels are different in these two regimes.

In the open economy, an autocratic regime controlled by a rich elite would reduce the regulation level to zero, making the rest of the population worse-off than under autarky (compare points b and $d$ in panel 1 of figure 5). In this sense, trade and the feasibility of private mitigation together bring out the worst aspects of the nondemocratic regime. In the democratic case, or speaking more generally, when lower income voters exercise political voice, the interests of the mass of voters swamp that of the rich. A stricter equilibrium regulation level of $\theta=0.7$ (that maximizes $S$ in 
the third panel of figure 5) emerges. In that case, collective choice leads to public action concerning environmental externalities because most voters cannot mitigate privately.

These patterns lead us to offer a final proposition and corollary about the relationship between environmental regulation and democracy:

Proposition 12 ('Democracy is good for environmental protection') When the health consequences of pollution can be mitigated privately at a cost, the nature of the political regime matters for the nature of equilibrium policy. In small open economies, public regulation of pollution will tend to be be stricter in democracies than in autocracies or in regimes governed by elites.

The corollary is that when private mitigation is feasible, poorer citizens are likely to lose from trade in non-democratic regimes, while gaining from trade in a fully competitive, democratic system. In contrast, the rich appear to gain from trade regardless of the regime type.

In assessing these results, it is important to recall that when private mitigation is infeasible, environmental regulation in the simulated equilibria of both democratic and non-democratic regimes are the same. So in the present framework, it is not simply the fact that the poor have voice in a democracy that distinguishes them. The interaction of the cost of private mitigation and the consequences of trade in determining the level and distribution of economic welfare is also crucial.

One should also note that the simulations we have conducted are based on particular choices of parameters. Strictly speaking, the convergence of policy choices across regime types when mitigation costs are very high, along with other results, should be regarded as conjectures, ones that we expect will hold in more general situations. From this perspective, propositions 11 and 12 are interesting hypotheses for empirical research.

As we noted in the introduction, both Congleton (1992) and Winslow (2005) argue that pollution control is greater in democracies because elites in non-democratic regimes receive a larger share of the income produced by the expansion of dirty industries, as they do in our framework. They also provide some empirical evidence to this effect. Propositions 11 and 12 point also to the critical role of costly private mitigation measures in the relationship between the type of regime and the nature of environmental control, which is not acknowledged in these interesting studies.

\subsection{Intensity of preferences and the democratic equilibrium}

In a last simulation, we illustrate our argument that when it comes to trade and pollution in the presence of private mitigation, intensity of preference along with the size of interest groups is likely to play a role in determining the outcome of the 

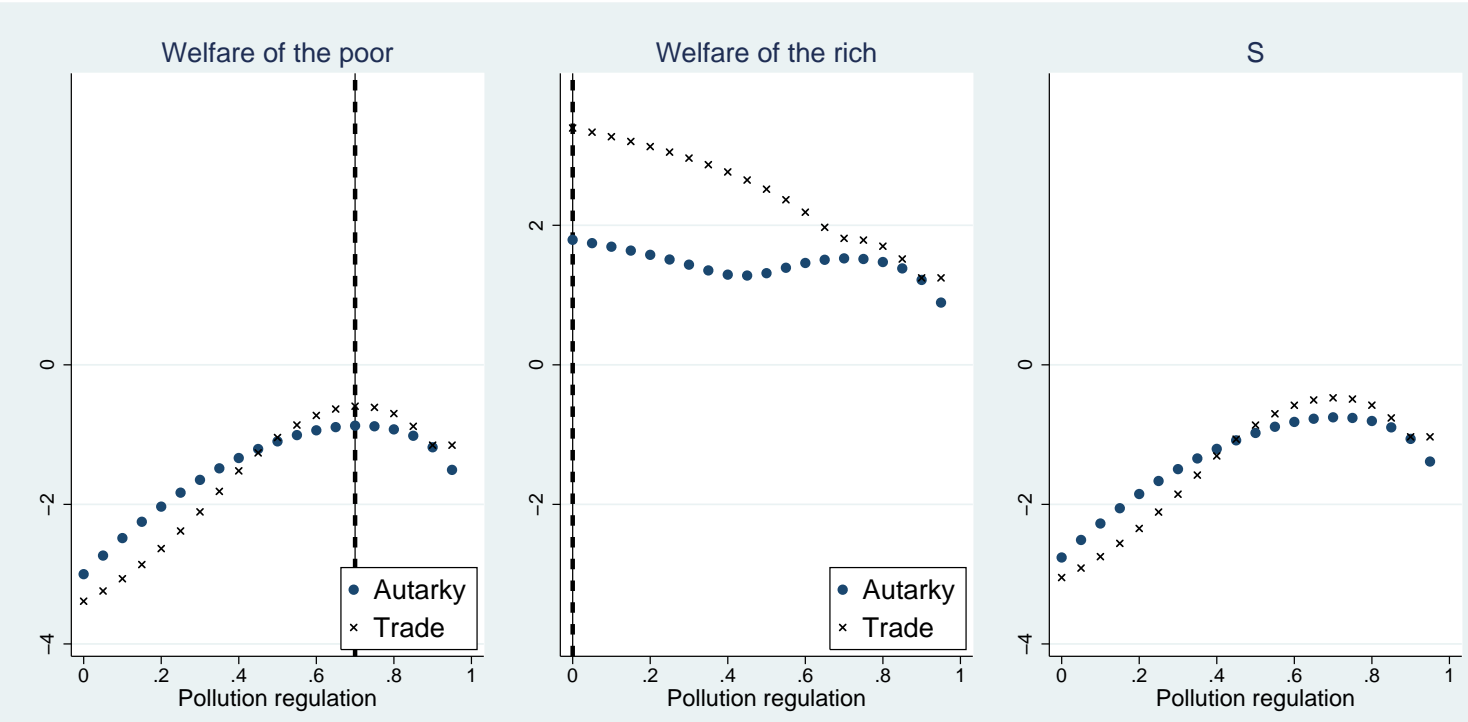

Figure 6: The role of the intensity of preferences $\left(\delta_{1}=0.4\right)$

democratic process. Given our representation of democratic political equilibria (26), the effect of a change in regulation on optimized political support is given by

$$
\frac{\Delta S}{\Delta \theta}=s \frac{\Delta V_{P}^{*}}{\Delta \theta}+(1-s) \frac{\Delta V_{R}^{*}}{\Delta \theta} .
$$

Here, population numbers interact multiplicatively with the sensitivities of welfare to changes in environmental controls - in other words, with the intensity of preferences for regulatory reform - to determine which way the policy equilibrium will change.

We have seen that trade exacerbates the divergence of interests between the poor and the rich. In expression (27), this translates into situations in which, for example, trade increases $\Delta V_{P}^{*} / \Delta \theta$ and reduces $\Delta V_{R}^{*} / \Delta \theta$. Figure 6 illustrates such a case. The only change from figure 5 here is that the private mitigation technology parameter is raised from 0.2 to 0.4 . This change - which reduces the effective cost of private mitigation - has little impact on the interests of the poor. But it is enough of a change to induce the rich to be well protected privately against the health effects of pollution in autarky when the level of regulation is low.

As a consequence, the rich now prefer that there be no public regulation at all, either with or without trade, while the poor still want some positive level of regulation. And this divergence of interests is exacerbated by a move to open trade.

We also see in figure 6 that as regulation increases, the welfare of the rich drops more sharply under trade than under autarky, while the welfare of the poor increases more sharply. So while the rich may not mind so much if there is stricter regulation 
under autarky, they may not be so pliable in an open economy. In a more complicated political setting than we have simulated, the rich may bargain harder before accepting stricter regulation when their welfare is relatively more sensitive to policy changes. And if commitment to policy is a problem from the perspective of the poor, one can envisage situations in which the poor vote against more open trade even though it has the potential to improve the welfare of everyone, because they fear that more lax regulation will then be introduced in the interests of the rich.

We complete our analysis at this point with a comparison to Verdier's (2004) work on trade integration. He argues that since trade openness affects a government's ability to redistribute, it is not possible to discuss the politics of globalization without also considering those of internal redistribution. In this paper, the ability to redistribute is not modeled explicitly. But in the analysis we have conducted, trade does raise the need for compensation of the poor due to the health effects of the pollution generated, and in a democratic equilibrium the rich essentially make sacrifices in their favor. In other words, when trade leads to environmental degradation, it is important to jointly analyze the distributive consequences of trade openness and of environmental regulation, and to do so in the presence of private mitigation, in order to understand public policy in either dimension.

\section{Conclusion}

We have analyzed in detail how the nature and heterogeneity of demands for public regulation of environmental externalities among citizens of differing incomes depend on the cost of private mitigation. And we have shown how the study of public policy towards regulation of the environment and of trade in dirty goods is altered when individual citizens can choose between costly collective and costly private alternatives for dealing with pollution.

To better isolate the role of private mitigation, we have broken the link between factor endowments and citizen interests employed in much of the existing literature on trade and pollution, because private mitigation of the consequences of domestic pollution depends solely on individual income regardless of its source. In the context of a small open economy, we then analyzed in detail how the benefits and costs of open trade in dirty goods interacts with choices concerning private mitigation to polarize the interests of citizens concerning the degree of environmental regulation. Even though trade openness leads to increased pollution, the possibility of using some of the extra income generated by trade for private mitigation may allow the wealthiest to actually shelter themselves so as to be less affected by pollution. Poorer citizens may not be in a position to afford such protection even after benefitting from the gains that open trade produces, and will tend to favor collective rather than private action. 
It follows from this analysis that the demands for trade openness are also heterogeneous with respect to direction and intensity, and are also importantly influenced by the possibility of private mitigation. For it matters what kind of trade, with what degree of pollution regulation, one considers when analyzing who is in favor and who is against more openness. It is not surprising, therefore, that introducing the ability to privately mitigate the consequences of pollution at a cost opens up a host of possibilities concerning the nature of environmental regulation and its relationship to trade openness in a political equilibrium.

We conclude that acknowledging the role of private mitigation of the consequences of pollution for health is essential for a full understanding of the political economy of the environment - trade - welfare nexus.

\section{APPENDIX}

Proof of proposition 5: The proof proceeds from the fact that the marginal pollution effect curve is continuous and non-increasing in $\alpha(i)$, as per proposition 4 . The idea is then to show that the trade curve is steeper than the autarky one, that it begins above it and ends below it.

(a) Since $\underline{\alpha}_{T}<\underline{\alpha}_{A}$, all individuals with $\alpha(i) \leq \underline{\alpha}_{T}$ choose $d^{*}(i)=0$, whether with trade or autarky. For them, the marginal pollution effect is equal to $-\delta_{0}(1-a) \Gamma^{\prime}(\theta) \hat{Z}_{2}$ in autarky and $-\delta_{0} \Gamma^{\prime}(\theta) \hat{Z}_{2}$ with trade (see $(25)$ ). Hence, the marginal pollution effect curve under trade is strictly above that of autarky at low $\alpha(i)$.

(b) For those who choose to be completely insulated from the effects of pollution, the marginal pollution effect is at the minimum value of zero. Since $\bar{\alpha}_{T}<\bar{\alpha}_{A}$, the marginal pollution effect is zero under trade for all $\alpha(i) \geq \bar{\alpha}_{T}$, while it is strictly positive under autarky for all $\alpha(i) \in\left(\bar{\alpha}_{T}, \bar{\alpha}_{A}\right)$. This implies that at $\bar{\alpha}_{T}$, the marginal pollution effect under trade is strictly below that of autarky and that for all $\alpha(i) \geq \bar{\alpha}_{T}$, the curve under autarky is not below the trade curve.

(c) For $\alpha(i) \leq \underline{\alpha}_{T}$, the slope is zero for both trade and autarky. For $\alpha(i) \in$ $\left(\underline{\alpha}_{T}, \bar{\alpha}_{T}\right)$, the slope under trade is strictly negative while it is either zero or strictly negative under autarky. Now the strictly negative slopes correspond to the interior value for $d_{k}^{*}(i)$ and are given by the following (see (25)):

$$
\frac{\partial}{\partial \alpha(i)}\left\{-\nu_{k}\left[\left(\delta_{0}-\delta_{1} d_{k}^{*}(i)\right) \Gamma^{\prime}(\theta) \hat{Z}_{2}\right]\right\}=\nu_{k}\left[\delta_{1} \Gamma^{\prime}(\theta) \hat{Z}_{2}\right] \frac{\partial}{\partial \alpha(i)} d_{k}^{*}(i), k \in\{A, T\} .
$$

According to (15), we have

$$
\frac{\partial}{\partial \alpha(i)} d_{k}^{*}(i)=\frac{Y_{k}}{c\left(p_{k}\right)}
$$


Since $Y_{A}=Y_{T}=(1-\theta) \hat{Z}_{2}, c\left(p_{A}\right)>c\left(p_{T}\right)$ and $\nu_{A}<\nu_{T}$, we have that the (negative) slope is steeper with trade than autarky.

Proof of proposition 6: The marginal price-income effects of regulation are given by the first terms between square brackets in (25) for all income shares. Taking the derivatives with respect to $\alpha(i)$ yields the following:

$$
\begin{aligned}
& \frac{\partial}{\partial \alpha(i)}\left[\nu_{k} \frac{1}{1-\theta}\right]=0 \quad \text { when } \alpha(i) \leq \underline{\alpha}_{k}, \\
& \frac{\partial}{\partial \alpha(i)}\left[\nu_{k} \frac{\alpha(i) \hat{Z}_{2}}{\alpha(i) Y-c(p) \frac{\delta_{0}}{\delta_{1}}}\right]<0 \quad \text { when } \alpha(i) \geq \bar{\alpha}_{k} \text {, } \\
& \frac{\partial}{\partial \alpha(i)}\left[\nu_{k} \frac{\alpha(i) \hat{Z}_{2}}{\frac{c(p)}{\delta_{1} Q}}\right]>0 \quad \text { when } \underline{\alpha}_{k}<\alpha(i)<\bar{\alpha}_{k} .
\end{aligned}
$$

Hence, the marginal price-income effect is initially constants up to $\alpha(i)=\underline{\alpha}_{k}$, is increasing for $\underline{\alpha}_{k}<\alpha(i)<\bar{\alpha}_{k}$ and is decreasing for $\alpha(i) \geq \bar{\alpha}_{k}$. The proof is complete by noting that the marginal effect is continuous at both $\underline{\alpha}_{k}$ and $\bar{\alpha}_{k}$, which can be verified by substituting the values in (16) and (17).

Proof of proposition 7: The marginal price-income effects of regulation are given by the first terms between square brackets in (25) for all income shares. For $\alpha(i) \in\left[0, \bar{\alpha}_{T}\right]$, the result is obtained by substituting for $\nu_{A}=1-a$ and $\nu_{T}=1$, and for $e_{A}^{*}(i)$ and $e_{T}^{*}(i)$ in (13) and (15). For $\alpha(i)>\bar{\alpha}_{A}$, one can verify that $\lim _{\alpha(i) \rightarrow \infty} d V_{k}^{*}(i) / d \theta=$ $-\nu_{k} /(1-\theta), \forall k \in\{A, T\}$. The result follows from the fact that $\nu_{T}>\nu_{A}$.

Proof of proposition 8: Let $\tilde{\alpha}_{k}$ denote the wealth level of an individual who is marginally indifferent between more or less regulation, given $\theta$. From (25), it can be verified that $\tilde{\alpha}_{k}$, if it exists, is unique and must be in an interior solution with respect to the pollution-mitigation effort. Moreover, $\tilde{\alpha}_{k}$ necessarily exists if there are some individuals who would prefer strictly more environmental regulation. $\tilde{\alpha}_{k}$ must be such that the price-income and pollution effects are equal; that is,

$$
\frac{\tilde{\alpha} \hat{Z}_{2}}{e_{k}^{*}(i)}=\left(\delta_{0}-\delta_{1} d_{k}^{*}(i)\right) \Gamma^{\prime}(\theta) \hat{Z}_{2} .
$$

From (15), we have that $e_{A}^{*}(i)>e_{T}^{*}(i)$ and $d_{A}^{*}(i)<d_{T}^{*}(i)$. Hence, the LHS of $(29)$ is higher with trade than autarky while the converse holds for the RHS. An indifferent individual in autarky will see his price-income effect of regulation strictly exceed the pollution effect with trade and specialization in the dirty good. The proof is made 
complete by the fact that the price-income effect increases with $\alpha(i)$ while the opposite holds for the pollution effect.

Proof of proposition 9: For all those whose pollution mitigating-effort is nil with trade, the gap between the marginal pollution effect and the marginal price-income effect is higher by a factor $1 /(1-a)$ when opening up to trade; their demand for additional regulation is thus more intense with trade. Among those who protect themselves partially, we have determined that income share $\tilde{\alpha}_{T}$ denotes the marginally indifferent individuals with trade and that the same individuals demanded strictly more regulation in autarky; the intensity of their demand for additional regulation has decreased with trade. By continuity of both marginal effect curves, an income share must exist which is comprised strictly between $\underline{\alpha}_{T}$ and $\dot{\alpha}_{T}$ and for which the intensity of the demand for additional regulation is equal in both autarky and trade. Concerning the wealthiest individuals, we have seen that for arbitrarily large income shares, the pollution effect is nil while the price-income effect increases with trade (proposition 7). Concerning intermediate income shares, it can be verified that although the priceincome effect of regulation peaks at $\bar{\alpha}_{k}$ in both trade and autarky, its magnitudes is higher with trade than autarky. Hence, by continuity of the curves, individuals with income shares located next to $\bar{\alpha}_{k}$ on both sides are more severely and negatively affected by regulation with trade than autarky.

\section{References}

[1] Mining in peru: Halting the rush against gold. The Economist, February 52005.

[2] Daron Acemoglu and James S. Robinson. Economic Origins of Dictatorship and Democracy. Cambridge University Press, 2006.

[3] Toke S. Aidt. Political internalization of economic externalities and environmental policy. Journal of Public Economics, 69:1-16, 1998.

[4] Timothy J. Bartik. Evaluating the benefits of non-marginal reductions in pollution using information on defensive expenditures. Journal of Environmental Economics and Management, 15:111-27, 1988.

[5] Philippe Bernard. La rage d'Espérance Edoukou, victime des déchets toxiques déversés à Abidjan. Le Monde 13.09.06, 13 Septembre 2006.

[6] Keith Bradsher and David Barbosa. Pollution from chinese coal casts a global shadow. The New York Times 11.06.06, June 112006. 
[7] Nancy Brooks and Rajiv Sethi. The distribution of pollution: Community characteristics and exposure to air toxics. Journal of Environmental Economics and Management, 32:233-250, 1997.

[8] B. Brunekreef and S.T. Holgate. Air pollution and health. The Lancet, 360:123342, 2002.

[9] Graciela Chichilnisky. North-south trade and the global environment. The American Economic Review, 84(4):851-874, September 1994.

[10] Roger D. Congleton. Political institutions and pollution control. The Review of Economics and Statistics, 74:412-421, 1992.

[11] B.R. Copeland and M.S. Taylor. North-south trade and the environment. Quarterly Journal of Economics, 109:755-87, 1994.

[12] B.R. Copeland and M.S. Taylor. Trade and the Environment: Theory and Evidence. Princeton University Press, Princeton, USA and Oxford, UK, 2003.

[13] Brian R. Copeland. Policy endogeneity and the effects of trade on the environment. Agricultural and Resource Economics Review, 34:1-15, 2005.

[14] Peter J. Coughlin. Probabilistic Voting Theory. Cambridge University Press, 1992.

[15] Peter J. Coughlin and Shmuel Nitzan. Electoral outcomes with probabilistic voting and nash social welfare maxima. Journal of Public Economics, 15(1):11321, February 1981.

[16] Paul N. Courant and Richard C. Porter. Averting expenditure and the cost of pollution. Journal of Environmental Economics and Management, 8:321-29, 1981.

[17] S. Dasgupta, K. Hamilton, K. Pandey, and D. Wheeler. Environment during growth: Accounting for governance and vulnerability. World Development, 34:1597-1611, 2006.

[18] Clas Eriksson and Joakim Persson. Economic growth, inequality, democratization, and the environment. Environmental and Resource Economics, 25:1-16, 2003.

[19] Mary F. Evans and V. Kerry Smith. Do new health conditions support mortalityair pollution effects? Journal of Environmental Economics and Management, 50:496-518, 2005. 
[20] Y.Hossein Farzin and Craig A. Bond. Democracy and environmental quality. Journal of Development Economics, 81:213-235, 2006. Paper presented at the 2005 Canadian Resource and Environmental Economics Annual Meeting, HEC Montreal.

[21] Robert C. Feenstra. Advanced International Trade: Theory and Evidence. Princeton University Press, 2004.

[22] Per G. Fredriksson. The political economy of pollution taxes in a small open economy. Journal of Environmental Economics and Management, 33:44-58, 1997.

[23] Per G. Fredriksson, Eric Neumayer, Richard Damania, and Scott Gates. Environmentalism, democracy, and pollution conrol. Journal of Environmental Economics and Management, 49:343-365, 2005.

[24] Howard W. French. Riots in Shanghai suburb as pollution protest heats up. The New York Times 19.0\%.05, July 192005.

[25] Brid Gleeson Hanna. House values, incomes, and industrial pollution. Journal of Environmental Economics and Management, 54:100-112, 2007.

[26] Walter Hettich and Stanley L. Winer. Democratic Choice and Taxation: A Theoretical and Empirical Analysis. Cambridge University Press, New York, 1999.

[27] Louis Hotte, Ngo Van Long, and Huilan Tian. International trade with endogenous enforcement of property rights. Journal of Development Economics, 62:25-54, 2000.

[28] Louis Hotte and Stanley L. Winer. Political influence, economic interests and endogenous tax structure in a Computable Equilibrium framework: With application to the united states, 1973 and 1983. Public Choice, 109:69 - 99, 2001.

[29] Seema Jayachandran. Air quality and early-life mortality: Evidence from Indonesia's wildfires. NBER Working Papers 14011, National Bureau of Economic Research, Inc, May 2008.

[30] Matthew E. Kahn and John G. Matsusaka. Demand for environmental goods: Evidence from voting patterns on California inititives. Journal of Law and Economics, XL:137-173, 1997.

[31] Bengt Kristrom and Pere Riera. Is the income elasticity of environmental improvements less than one? Environmental and Resource Economics, 7(1):45-55, January 19961996. 
[32] Carol McAusland. Voting for pollution policy: The importance of income inequality and openness to trade. Journal of International Economics, 61:425-451, 2003.

[33] Ross McKitrick and Robert A. Collinge. The existence and uniqueness of optimal pollution policy in the presence of victim defense measures. Journal of Environmental Economics and Management, 44:106-122, 2002.

[34] Matthew J. Neidell. Air pollution, health, and socio-economic status: The effect of outdoor air quality on childhood asthma. Journal of Health Economics, 23:1209-1236, 2004.

[35] J. Pearce, S. Kingham, and P. Zawar-Reza. Every breath you take? environmental justice and air pollution in Christchurch, new zealand. Environment and Planning A, 38:919-938, 2006.

[36] R. Pethig. Pollution, welfare, and environmental policy in the theory of comparative advantage. Journal of Environmental Economics and Management, 2:160169, 1976.

[37] Marcia A. et Al. Rosado. Combining averting behavior and contingent valuation data: An application to drinking water treatment in Brazil. Environment and Development Economics, 11:729-746, 2006.

[38] Joachim Schleich. Environmental quality with endogenous domestic and trade policies. European Journal of Political Economy, 15:53-71, 1999.

[39] Hirofumi Shibata and J. Steven Winrich. Control of pollution when the offended defend themselves. Economica, 50:425-437, 1983.

[40] Mariano Torras and James K. Boyce. Income, inequality, and pollution: A reassessment of the environmental Kuznets curve. Ecological Economics, 25:147160, 1998.

[41] Thierry Verdier. Socially responsible trade integration: A political economy perspective. Discussion Paper Series 4699, CEPR, 2004.

[42] Margrethe Winslow. Is democracy good for the environment? Journal of Environmental Planning and Management, 48:771-783, 2005. 